Recebido em 04/2016. Aceito para publicação em 06/2016.

\title{
INFLUÊNCIA DA CONCENTRAÇÃO DE OLIGONUCLEOTÍDEOS NO EFEITO DE AGLOMERAÇÃO DE NANOPARTÍCULAS NA PRESENÇA DE SOLUÇÃO SALINA
}

\author{
INFLUENCE OF OLIGONUCLEOTIDE CONCENTRATION IN THE NANOPARTICLE \\ AGGLOMERATION EFFECT IN A SALT SOLUTION
}

\author{
Olavo de Osti Comparato Filho' \\ Marcela Aparecida Cândido ${ }^{2}$ \\ Guilherme Mosquim Lemes ${ }^{3}$ \\ Leandro José Raniero ${ }^{4}$
}

Resumo: O desenvolvimento de tecnologias que auxiliam no estudo da interação de nanopartículas com biomoléculas tem proporcionado o surgimento de novas técnicas de diagnóstico de doenças. Nanomateriais possuem características químicas e físicas específicas, como o efeito de ressonância plasmônica de superfície (SPR). Este trabalho parte do princípio da utilização de nanopartículas de Ouro (AuNPs), previamente sintetizadas e padronizadas, para o estudo da influência de concentrações de oligonucleotídeos, em presença de solução salina de Cloreto de Magnésio hidratado ( $\mathrm{MgCl}$.6H2O), na sua estabilidade coloidal, por meio da Espectroscopia de UV-visível. No laboratório de nanossensores, realizaram-se experimentos com nanopartículas, oligonucleotídeos e sal, onde se observou, por meio de testes colorimétricos, a influência da porcentagem de cobertura das superfícies das nanopartículas das soluções finais, nos efeitos da SPR. Os resultados gráficos dos experimentos, dos espectros UV vis que relacionam absorbância e comprimentos de onda, registraram o processo de aglomeração. O objetivo foi analisar comparativamente a influência da concentração dos oligonucleotídeos nas soluções com nanopartículas e sal, para a elaboração das curvas de estabilidade das AuNPs.

Palavras-chave: oligonucleotídeos; nanopartículas de Ouro; ressonância plasmônica de superfície; processo de aglomeração.

Abstract: The development of technologies in the study of nanoparticles interaction with biomolecules has been used as new techniques in diseases diagnostics. Nanomaterials have specific chemistry and physics properties such as the surface plasmon resonance (SPR). In this work, the influence of $\mathrm{MgCl} 2.6 \mathrm{H} 2 \mathrm{O}$ salt solution on colloidal stability of the gold nanoparticles was studied as function of oligonucleotides concentration by of UV-vis spectroscopy. The experiments were done at Nanossensors laboratory using nanoparticles, oligonucleotides and $\mathrm{MgCl} 2.6 \mathrm{H} 2 \mathrm{O}$ salt. The experiments results reveal values of absorbance and wavelength, which showed the agglomeration process. The aim was analyses comparatively the influence of the oligonucleotides concentration in the nanoparticles solutions with the addition of salt solution to determine the curves of stability.

Keywords: oligonucleotides; Gold nanoparticles; surface plasmon resonance; agglomeration process.

\footnotetext{
${ }_{1}^{1}$ Mestrando em Física e Astronomia - Laboratório de Nanossensores - da Universidade do Vale do Paraíba UNIVAP, Brasil. E-mail: ocfilho69@hotmail.com.

${ }^{2}$ Graduanda em Engenharia Química da FEAU - Laboratório de Nanossensores - Universidade do Vale do Paraíba - UNIVAP, Brasil. E-mail: marcela.aparecida.candido@gmail.com.

${ }_{3}^{3}$ Graduando em Engenharia Química da FEAU - Laboratório de Nanossensores - Universidade do Vale do Paraíba - UNIVAP, Brasil. E-mail: gui.lemes10@gmail.com.

${ }^{4}$ Doutorado em Engenharia de Materiais pela Universidade Nova de Lisboa, Portugal. Professor Doutor da Universidade do Vale do Paraíba - UNIVAP / Instituto de Pesquisa e Desenvolvimento - IP\&D - Laboratório de Nanossensores, Brasil. E-mail: Iraniero@univap.br.
} 


\section{INTRODUÇÃO}

Os nanomateriais apresentam propriedades distintas das propriedades das moléculas e dos sólidos cristalinos típicos, devido aos efeitos da relação entre o volume em relação à área superficial evidente para dimensões nanométricas. $O$ desenvolvimento de tecnologias que possibilitam a monitorização da interação desses materiais com biomoléculas tem impulsionado a inovação de técnicas e dispositivos de diagnóstico e de terapêutica. Os avanços tecnológicos nessa área levaram ao aparecimento de novos ramos de conhecimento, como, por exemplo, a Nanobiotecnologia e a Nanomedicina (MARTINS; TRINDADE, 2012). Considerando uma nanopartícula esférica, a redução do seu diâmetro aumenta a relação entre átomos na superfície por átomos no volume, evidenciando as propriedades químicas e físicas dos nanomateriais.

A síntese de nanopartículas de Ouro forma uma solução coloidal. Irradiadas na região visível do espectro eletromagnético dão origem ao efeito de Ressonância Plasmônica de Superfície (SPR), que consiste na oscilação coletiva de elétrons livres, produzindo absorções (MARTINS, 2012). Mudanças sutis no meio podem promover alterações significativas na ressonância, em virtude do processo de desestabilização, que leva à aglomeração. Conforme mostrado na Figura 1, nanopartículas de Ouro dispersas ou estabilizadas apresentam coloração vermelha ou vinho, com banda de SPR centrada na região dos $523 \mathrm{~nm}$. Quando ocorre o efeito de aglomeração, apresentam a coloração roxa ou azul. Neste caso, o centro da banda SPR desloca-se para $650 \mathrm{~nm}$.

Um dos principais fatores que contribuem para o aumento da estabilidade coloidal é a repulsão eletrostática, ou seja, uma tendência de afastamento entre partículas eletrizadas ou cargas de mesmo sinal; que evita a sua aglomeração e precipitação. Outro fator é a formação de uma película protetora em torno da partícula coloidal, denominada camada de solvatação, quando íons ficam envoltos por moléculas de solvente. Por outro lado, para precipitar um coloide, podemos neutralizar as cargas elétricas das partículas ou eliminar a camada de solvatação.

Essas nanopartículas podem atuar como nanossensores, ligando biomoléculas, como proteínas, DNA, entre outros.

Os oligonucleotídeossão fragmentos curtos de uma cadeia simples de ácido nucléico, sendo frequentemente usados como sondas para detectar DNA complementar.

O objetivo principal deste trabalho é fazer uma análise comparativa da influência da concentração de oligonucleotídeos no efeito de aglomeração de nanopartículas na presença de uma solução salina $(\mathrm{MgCl} 2.6 \mathrm{H} 2 \mathrm{O})$. 


\section{METODOLOGIA}

\subsection{Síntese de nanopartículas}

A primeira etapa envolveu a preparação da solução de nanopartículas de Ouro, que foi realizada com base na metodologia descrita por Lee e Meisel, de 1982, que possibilita a síntese de AuNPs esféricas com diâmetro em torno de $22 \mathrm{~nm}$. Inicialmente, foram adicionados $25 \mathrm{~mL}$ da solução de Cloreto de Ouro $\left(\mathrm{HAuCl}_{4}\right)$ na concentração de $1,41 \mathrm{mM}$, a $450 \mathrm{ml}$ de água ultrapura; aquecidos até $95^{\circ} \mathrm{C}$ e agitados a 1000 r.p.m. O processo é finalizado adicionando-se $50 \mathrm{~mL}$ de uma solução de Citrato de Sódio $\left(\mathrm{C}_{6} \mathrm{H}_{5} \mathrm{Na}_{3} \mathrm{O}_{7}\right)$ na concentração de $5,65 \mathrm{mM}$. A solução foi mantida por uma hora em aquecimento e permanecendo em agitação até o resfriamento a $45^{\circ} \mathrm{C}$ (VIEIRA, 2012).

\subsection{Biomolécula}

A estabilização das nanopartículas de ouro foi feita por meio de oligonucleotídeos (oligo), que foram adquiridos da empresa Sigma-Aldrich. As sequências são mostradas na Tabela 1.

\section{Tabela 1 - Descrição das sequências}

\begin{tabular}{ccccccc} 
Oligos & Leng & MW & $\mu \mathrm{g}$ & $\mathrm{nmol}$ & $\mathrm{GC} \%$ & Sequência \\
\hline 1 & 21 & 6332 & 379.7 & 59.9 & 47.6 & TCGCTTCCTCATGACAGACTT \\
\hline 2 & 21 & 6261 & 465.7 & 74.3 & 47.6 & TCACCTGCATCCACCATACTT
\end{tabular}

Fonte: Autor.

\subsection{Testes de estabilidade}

A análise de caracterização foi feita por espectroscopia no UV-VIS, utilizando um espectrofotômetro, modelo Denovix S11.

Para os experimentos dos testes de estabilidade de nanopartículas, por meio de oligonucleotídeos e sal, foram necessários alguns cálculos preliminares para a utilização de volumes e concentrações adequados. A concentração das nanopartículas foi calculada por meio do valor de absorbância da região da SPR em $523 \mathrm{~nm}$, utilizando a Equação 1.

\section{Equação 1 - Cálculo da concentração das nanopartículas}

$$
C=\frac{A}{\in . b}
$$


Sendo $\boldsymbol{A}$ o valor da absorbância, $\boldsymbol{b}$ o caminho óptico do equipamento, e $\boldsymbol{\epsilon}$ o coeficiente de extinção do Ouro $\left(1,0 \times 10^{9} \mathrm{M}^{-1} \mathrm{~cm}^{-1}\right)$.

Para os oligonucleotídeos, o peso molar de cada um deles, em g/mol; quantidade e sequência de bases foram calculadas conforme exemplificado na Tabela 1. No cálculo do recobrimento da área da nanopartícula por oligos, foi feita uma aproximação onde as nanopartículas foram consideradas como perfeitamente esféricas e as fitas simples das bases nitrogenadas possuíssem áreas retangulares. Assim foi possível obter a relação entre áreas de cobertura das "fitas" com relação à área da esfera da nano (CASTILHO, 2012). Os testes de estabilidade foram baseados na preparação de soluções com os volumes: $5 \mu \mathrm{L}$ de nanopartículas de Ouro e $2 \mu \mathrm{L}$ de oligonucleotídeo em determinada concentração. Em seguida, colocadas em "banho Maria" a $33^{\circ} \mathrm{C}$ por $4 \mathrm{~min}$, acelerando o processo de reação. Por fim, as amostras receberam $1 \mu \mathrm{L}$ do sal $\mathrm{MgCl} 2.6 \mathrm{H} 2 \mathrm{O}$ a 2,6 mM e foram homogeneizadas por $3 \mathrm{~min}$ antes da medição no espectrofotômetro.

\section{RESULTADOS E DISCUSSÃO}

As nanopartículas sintetizadas mostraram características típicas de uma solução coloidal de nanopartículas de Ouro, como mostrado na Figura 1 (a). A concentração medida foi de $2,45 \times 10^{15}$ partículas por litro (Equação 1). Quando adicionada à $\mathrm{MgCl} 2.6 \mathrm{H} 2$ a 2,6 mM, a solução aglomerou, conforme mostrado na Figura 1 (b).

Figura 1 - Nanopartículas de Ouro estabilizadas (a) e aglomeradas (b).

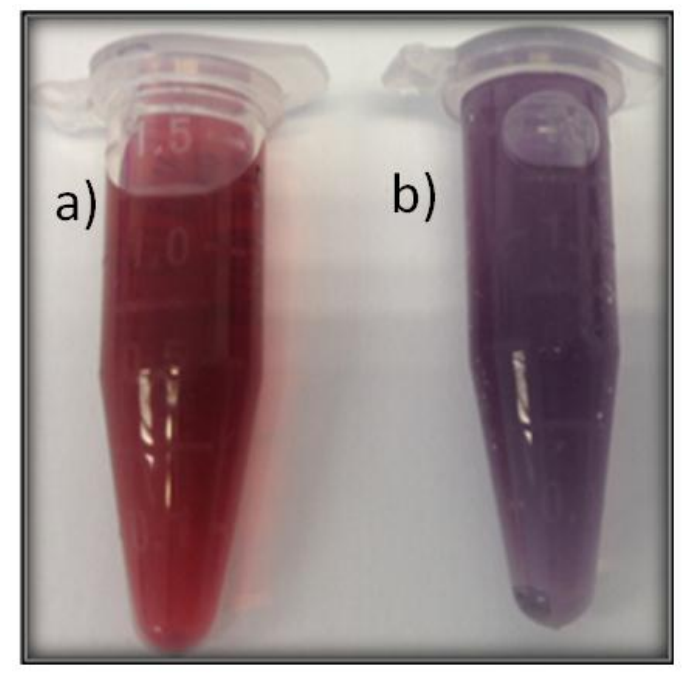

Fonte: Autor.

No caso do oligonucleotídeo utilizado, a relação entre as áreas da superfície esférica da nano e de uma fita simples foi de 163,81. Dessa forma, a concentração pôde ser calculada e o valor foi de $6,68 \times 10^{-7} \mathrm{~mol} \mathrm{~L}^{-1}$. Com esses dados, foi calculada a 
quantidade necessária para cobertura percentual da superfície de 10,40, 70 e 90. Os testes foram realizados e os resultados foram satisfatórios, observando a curva de estabilidade das nanopartículas e da resposta colorimétrica.

Os resultados podem ser observados nas Figuras 2 e 3.

Figura 2 - Curva de estabilidade

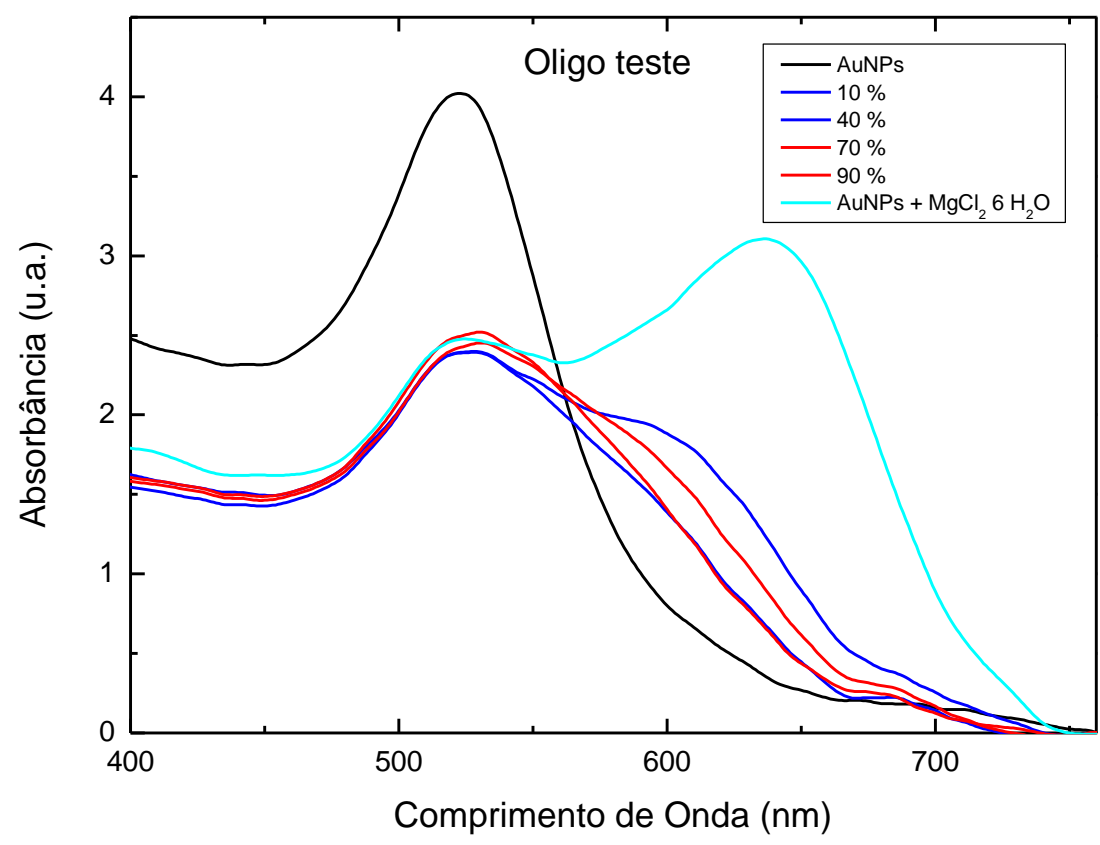

Fonte: Autor

A curva de estabilidade mostra a banda de absorção das nanopartículas dispersas sem adição da solução salina, centrada em 523 nm (espectro de cor preta). $\mathrm{Na}$ presença da solução salina, a medida que a cobertura superficial dessas partículas, feita pelos oligonucleotídeos, foi diminuindo (porcentagens 90, 70, 40 e 10), essa banda foi se deslocando para $650 \mathrm{~nm}$. As curvas representadas em vermelho indicam pouca aglomeração das nanopartículas. As curvas representadas em azul indicam maior aglomeração das nanopartículas. Enquanto a curva representada pela cor azul clara indica uma característica de nanopartícula adiconada ao sal, onde-se verifica um maior ponto de absorção em $650 \mathrm{~nm}$. 
Figura 3 - Teste colorimétrico

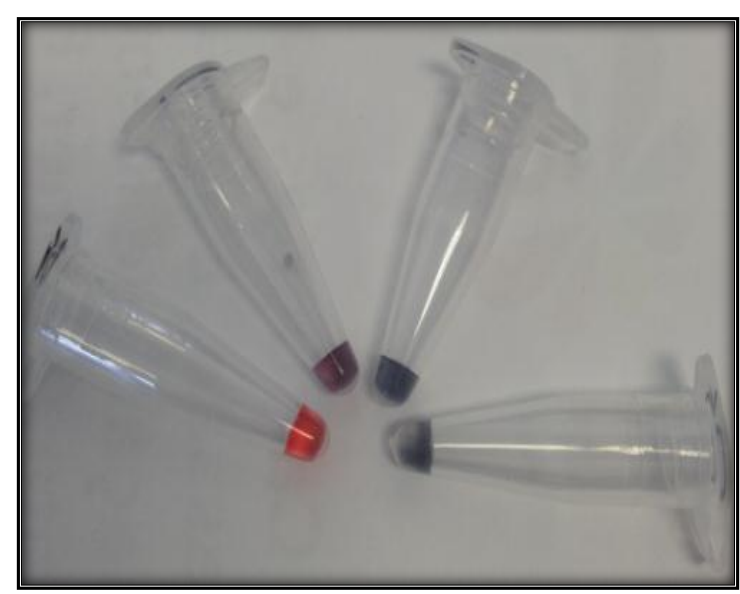

Fonte: Autor.

Por meio do teste colorimétrico, observou-se a evolução da aglomeração de nanopartículas em função da variação de cobertura de sua área pelos oligonucleotídeos.

\section{CONCLUSÃO}

Foi possível verificar que, à medida que a concentração dos oligonucleotídeos aumenta, ou seja, em que a porcentagem de cobertura da superfície da nanopartícula por eles se eleva; maior o retardamento do processo de aglomeração na presença de solução salina ou desestabilização das nanopartículas, alterando sua coloração inicial vermelha ou vinho, para roxa ou azul e deslocando sua banda de absorção máxima em $523 \mathrm{~nm}$ para a banda de $650 \mathrm{~nm}$.

\section{AGRADECIMENTOS}

Os autores agradecem à CAPES pela concessão de bolsa de Mestrado e bolsa de Iniciação Científica. Ao CNPq pelo apoio dos projetos 301022/2012-7 e 470534/2012-5.

\section{RERERÊNCIAS}

CASTILHO, M. L.; Diagnóstico por nanopartículas de ouro funcionalizadas com fragmento do gene GP27 do Paracoccidioidies brasiliensis. São José dos Campos, 2012. 29 f. Trabalho de conclusão de curso (Engenharia Biomédica). Faculdade de Arquitetura e Urbanismo. Universidade do Vale do Paraíba, São José dos Campos, 2012.

MARTINS, J. F. S. Identificação do fungo Paracoccidioides Brasiliensis por 
nanossondas de ouro. São José dos Campos, 2012. 80 f. Dissertação (Mestrado em Eng. Biomédica) - Universidade do Vale do Paraíba, São José dos Campos, 2012.

MARTINS, M. A.; TRINDADE, T. Os nanomateriais e a descoberta de novos mundos na bancada do químico. Química nova, v. 35, n. 7, p. 1434-1446, 2012.

VIEIRA, L. S.; Síntese e caracterização de nanopartículas de Ouro encapadas com prata. São José dos Campos, 2012. 27 f. Trabalho de conclusão de curso (Engenharia Química). Faculdade de Engenharia, Arquitetura e Urbanismo. Universidade do Vale do Paraíba, São José dos Campos, 2012. 